\title{
Human Resource Management Outsourcing in Spanish firms: Evolution over time and implication for devolution
}

\author{
Debora Gottardello(D), Mireia Valverde (iD \\ Universitat Rovira i Virgili (Spain) \\ debora.gottardello@urv.cat,mireia.valverde@urv.cat
}

Received July, 2017

Accepted January, 2018

\section{Abstract}

Purpose: The paper aim to explore the evolution in the use of HRO in Spanish firms, and determine the differences in the degree of implementation of HRO since 1999 until 2014, and also analyze the relationship between HR outsourcing and devolution of HR responsibilities to line managers in Spanish organizations.

Design/methodology: This paper combines quantitative and qualitative methods. Namely the article is based on international Cranet HRM survey data collected from private and public organizations and also interviews with HR external providers.

Findings: The analysis of developments, based on the Cranet surveys and interviews with HR external providers shows that during the past few years there has been an increasing use of HRO in parallel with the tendency to devolve more HR responsibility to line managers.

Research limitations/implications: The main limitation of this research is the limitation of data about reasons for devolution that the CRANET questionnaire provides. However, the interviews carried out enrich the survey data with qualitative results.

Practical implications: The findings can be used to guide management teams in outsourcing and devolution decisions to maximize benefits to their organizations.

Originality/value: This paper is about the evolution of HRO in Spain as a European Union country where published research on $\mathrm{HRO}$ and also its implications is relatively limited. The originality of this paper is mainly the involvement of line manager in the outsourcing process which have been poorly analyzed until now.

Keywords: Outsourcing, Human resources, Devolution, Administrative activities, Supply chain management

Jel Codes: J24, J39, O15, O12, M12, M51, M54

\section{Introduction}

With the purpose to achieve greater flexibility in many areas of activity and in order to face the complexity of the current business environment, firms have tended to implement reforms in their systems, structures, and other organizational aspects, as well as to undertake a variety of initiatives to improve financial return and 
incomes, such as the establishment of organizational matrixes, networks tied together by temporary relationships, cooperation and outsourcing (Kenyon, Meixell \& Westfall, 2016; Vasconcelos \& Ramirez, 2011). In this way, many firms decide to outsource some policies designed to maximize organizational integration, employee commitment, flexibility and quality of work (Guest, 1987). This is the case of outsourcing human resource management activities with the purpose of constantly looking fora more streamlined organizational structure, focusing on core activities. As shown by many studies, there has been a tremendous increase in the HRO of over the last decade. However, despite the evolution that have experienced outsourcing in the Human resources context, when reviewing the research on this field it is noted that there has been scarcely any research that have empirically analyzed the evolution of HRO in Spanish organizations nor those who have examined the relationship between HR outsourcing and devolution of HR responsibilities to line managers. Consequently, this study aim to carry out a longitudinal investigation of the developments in the use of HRO in Spain. The study also seeks to analyze the profile of Spanish firms outsourcing more and less intensively, as well as how their use of HRO is related to other HR function characteristics, such as the strategic position of the HR department, degree of devolution and formalization of HR policies and practices. Therefore, the key questions we ask in this paper are: How has HRO evolved over time in the Spanish context? When facing the dilemma of whether HRO is widely used when HR department decide to not devolve to line manager HR function, is reliance on HRO bigger when the HR department is responsible for a particular HR function? In order to structure these questions, we now develop their conceptual bases.

\section{Literature review and hypotheses development}

Human resources outsourcing (HRO) involves contracting out (Lilly, Gray \& Virick, 2005; Tremblay, Patry \& Lanoie, 2008) qualified expertise to handle certain Human Resources (HR) activities outside the organization in order to gain access to specialized technical capabilities and services (Klaas, McClendon \& Gainey, 2001), and thus manage more quickly and efficiently specific HR issues. Facing cutthroat competition, cost pressures and internationalization, more and more organizations rely on outsourcing and, in particular, HRO, to uphold profitability and ensure survival (Lahiri, 2015). Therefore, HR department has new responsibilities as potential vehicles for change (Conklin, 2005) and are required to revisit past decisions and even implement or find new ways of managing its workforce through new ideas or up-to date HR policies (Alewell, Hauff, Thommes \& Weiland, 2009).

From the literature we can observe that the outsourcing of HR activities is driven by different reason such as: economic and strategic reasons (Belcourt, 2006; Hung Lau \& Zhang, 2006).

The economic reason is the need of firms to cut costs, such as operational and labor cost in order to improve profitability and add value and save cost with the aim to gain efficiency and improve revenues (Hung Lau \& Zhang, 2006). More typical strategic reasons have recently distinguished HRO, including focus on core competences, ensure organization's position in the marketplace (Hartman, Ogden \& Hazen, 2017), call for participation of HR departments in strategic issues, achieve greater business flexibility, improve quality by achieving economies of scale, gain access to specialized HR external expertise (Butler \& Callahan, 2014; Chiang, Chow \& Birtch, 2010; Delmotte \& Sels, 2008; Gilley, Greer \& Rasheed, 2004; Glaister, 2014; Klaas et al., 2001; Klaas, McClendon, \& Gainey, 1999; Quartey, 2013) who have competency in the areas concerned and can offer excellent quality and efficiency (Tremblay et al., 2008; Woodall, Scott-Jackson, Newham \& Gurney, 2009). In this context, outsourcing some HRM functions can be seen as an opportunity for the internal HR departments (Delmotte \& Sels, 2008) as they can focus on what the organization does best, and contract everything else outside (Belcourt, 2006). Despite these benefits, HRO is not an incontrovertible panacea (Shen, 2005). Indeed, research reveals that there are many risks that can be derived from implementing HRO in organizations (Cooke, Shen \& Mcbride, 2005; Woodall et al., 2009) such increase costs instead of saving them, HR department's loss of internal knowledge, skills and expertise (Greer, Youngblood \& Gray, 1999; Kosnik, Wong-MingJi \& Hoover, 2006; Shen, 2005), lack of efficiency and experience of the service provider, the risk that the service suppliers hand over the acquired know-how to competitors, or less flexibility as a result of the suppliers' request of longterm contracts to benefit from stable revenues (Cooke et al., 2005). 
Even with its inherent risks and accounts of both successes and failures, HRO (HRO) seems to be, particularly in the practitioner literature, an ever-increasing phenomenon, and its growth took place alongside with the economic downturn which affected negatively the business environment especially the industrialized and developed nations (Iqbal \& Dad, 2013). According to Saintemarie (2011) notwithstanding the economic recession and the consequent financial loses the outsourcing services market has continued to growth in European countries. He showed that by the end of 2009, Poland had created almost more than 10,000 new jobs in the outsourcing industry. Similarly, in Spain a study carried out by CTC (GrupoUno CTC, 2015) pointed out that the economic crisis in Spain boosted the growth of outsourcing which "has experienced an increase of more than $50 \%$ in 2010, passing from being used by 33\% of companies in 2009 to $51 \%$ in $2011 "$ ". In the context of economic recession, the development of outsourcing services rises significantly as a way to strengthen the competitive position of Spanish companies and, in some cases, even facilitate their own survival (MonterreyMeana, 2013). High levels of uncertainty like this has the potential to enhance the ability of HR external providers to perform better than internal HR departments, due to their skill capabilities and ability to focus on specific HR issues (Lilly et al., 2005). Whereas, in stable and foreseeable economic environment, outsourcing the HR function, seems neither necessary nor appropriate as all competitors in the marketplace know what needs to be done in the market.

Different means have been used, and are still being used by many organizations in order to adapt to the new scenario and deal with the economic crisis more effectively (Fabregá \& Nicolau, 2016), such as reduce their cost, sell goods and assets available (Edvardsson \& Teitsdóttir, 2015) or even focus on core activities (Sanders, James, West, Locke, Moore \& Autry., 2007). Thus, among the existing practices, firms consider the possibility to outsource as a springboard for profit- generating activity that, when in accordance with the firms' strategy, help to raise incomes and gain competitive advantages (Beregszaszi \& Hack-Polay, 2015). The impact of the financial recession that began in early 2007, has been particularly severe and long-lasting, having resulted not only in lossesin markets and financial institutions, but also in the ways firms manage HR. Therefore firms have been forced to introduce a wide range of cost-cutting measures to sustain their survival, including investment in specific roles of HRM (Lai, Saridakis, Blackburn \& Johnstone, 2016). Following the economic and financial crisis suffered by Europe, numerous studies in the personnel selection literature identified a number of changes in the function of HR department which both operate with different parameters (Glaister, 2014) and "no longer perform the same functions as before" (Cappelli, 1999) devolving more activities to line managers and thus giving them more self-reliance in this area and outsourcing more and different HRM areas. In this particular situation the reasons of why HR department decide to devolve HR activities to line managers along with the growth of HRO may be due to the reduction of the HR department work (Larsen \& Brewster, 2003). According to Holt Larsen and Brewster (2003) the general trend to devolve more HR responsibility to line Manager has also led to a series of problems such as the poor HR professional training and competences, the lack of time or excessive overload to carry out those activities, the unawareness about new trends to manage employee or even knowledge about the topic. Furthermore, line manager are hesitancy to undertake HR responsibilities, considering this task as a merely personnel function that has nothing to do with their job (McGovem, HopeHailey \& Stiles, 1989). In a case study carried out by Cunningham and Hyman (1995), a series of constraints were identified when HR manager devolve personnel task to line manager, namely the lack of technical skills and insufficient training on how to carry out HR activities and the limited resources at its disposal, leading to more outsourcing of HR activities. Furthermore Larsen and Brewster (2003) noted that in Europe the HR function is increasingly assigned to line managers with the consequent reduction of HR department's work and responsibility and this consequential increased of devolution have come out together with the growth of HR outsourcing and Reichel and Lazarova, (2013) that, on the contrary, showed how outsourcing is less frequent in organizations where many of the traditional HR role are devolved to the line manager, but whose studies did not included Spain. These issues highlight the existence of a gap in the literature about this subject which hinders its understanding, holding back the development of its knowledge in the Spanish context. Thus, a comprehensive analysis of the evolution of HR outsourcing is imperative to gaining a proper understanding of the constantly updating HRO field. In this article, we conduct a comparative study that can aid the mapping of the field of HRO research. This approach allows us to identify the evolution in the use of HRO. 
The findings can help to understand the genesis and current state of the field, meaningful and helpful route for future research can hopefully be found based on this paper. In addition, this research aims to show whether and how outsourcing of human resource activities has grown during the last few years in the Spanish context. Over the last 20 years one of the most striking changes in our country has been the growth in the service sector (Bart, Mary \& Marcel, 2008). In this context HR outsourcing has steadily increased, and has become a strategic decision for companies seeking to monitor their costs and maintain a competitive advantage (Espino Rodríguez \& Padrón Robaina, 2006; Maley, Kowalkowski, Brege \& Biggemann, 2015). In this research, we use a temporal and industrial proximity perspective in order to identify the process underpinning the diffusion of HR outsourcing across firms within Spain. .Based on the above argumentation, we hypothesize:

\section{H1: HR outsourcing intensity has increased significantly in recent years, namely from 1999 to 2014.}

For quite some time, there has been an announced tendency toward the decline in HR unit's overall responsibility (Schuler, 1990). In parallel there are signs that organizations where the HR unit reduces the number of tasks for which it is responsible, tend both to devolve more HR activities to line managers and to outsource more HR responsibilities (Larsen \& Brewster, 2003). Thus, based on the above argumentation our second aim is two fold: understand the growing trend of outsourcing and impact of the devolution of some HR tasks and responsibilities to line managers. Namely, this aim breaks down further into an interrelated research question, which is the next step in order to shed light on this issue. By exploring HR external providers' perception about the reason why outsourcing is increasingly used by organization this study seek to get a greater understanding of why organization devolve more and at the same time outsource more. We also explored their views in terms of the main HR activities outsourced by Spanish organizations. Hence, upon close attention to the literature, the research question that guided this study are formulated as follows:

Does a strong focus on HRM devolution explain the increasing trend toward HR outsourcing?

\section{Research methodology}

\subsection{Research method}

To test our hypothesis and answer our research question, the research methodology followed a mixed methods approach in two distinct stages.

- Stage 1- quantitative data from the CRANET cross-national survey, run in Spain in 1999 and 2014. The CRANET is a research collaboration between universities and business schools from over 40 countries (Brewster, Mayrhofer \& Reichel, 2011; Dewettinck \& Remue, 2011; Parry, Stavrou-Costea \& Morley, 2011).

This data source allowed us to obtain HRO information from senior HR officers across a large number of Spanish firms of 200 or more employees. The age of the data set is important since the questions being tested here attempt to provide evidence of HRO and how this has developed over time. The data collection modes for the survey were postal questionnaires in the 1999, and recently (2014 round), new technologies have made it easier to obtain data with an online survey.

- Stage 2- exploratory qualitative interviews: we sought to examine underpinning explanations provided by HR external providers, thus gaining an understanding of the meaning they give of particular experiences related to practicing HR Outsourcing by organizations. Thus five interviews with HR external providers were carried out, to explore the research question we proposed, gain deeper insights into the emerging issues and understand the devolution of HR functions and use it in order to answer to our research question which is the second step of the research and thus be able to use it a source of corroboration and strength of the research hypothesis. 


\subsection{Sample}

Before the analysis, we detail the main features of the sample. The sample includes data provided by respondents from more than 373 companies operating in Spain between 1999 and 2014. As the CRANET survey varies slightly between rounds, variables related to the topic of interest have needed to be re-codified in order to be able to compare across the years. The breakdown of the sample is 275 organizations in 1999 and 98 in 2014. In $1999,50.9 \%$ were in the primary plus secondary sector, and $49.1 \%$ in the tertiary sector. In $2014,40 \%$ were in the primary and secondary sector and $60 \%$ in the tertiary. Regarding the size of the firms measured by number of employees, in 1999 roughly 233 companies (accounting for 88.3\%) are large enterprises with more than 250 employees globally, while in 2014, 71 large firms are observed, representing $72.4 \%$. In 1999, the medium size firms (from 50 to 249 employees) represent $11.4 \%$ of our sample while in 2014, 27.6\%.

\subsection{Measures}

The results obtained from CRANET cross-national survey, run in Spain in 1999 and 2014, offer insight about the intensity of use of outsourcing for the provision of HRM services. This question for the 1999 and 2014 questionnaires identifies four types of HRM activities, namely:

- Compensation and benefits

- Recruitment and selection

- Training and development

- Workforce outplacement

For the mentioned list of four HR activities (Table 1) the respondents were asked to specify whether the HR function in question was being provided by an external organization (value $1=$ the HR activity is being outsourced; value $0=$ the HR activity is not being outsourced).

In order to assess the degree to which firms outsource different areas of human resource management, the answer to these dichotomous variables were added, thus creating a new variable using a 4 point scale, between 0 (no HR activities outsourced) and 4 (all HR activities considered being outsourced). We therefore choose to create this variable in order to provide a comprehensive measure of the firm's reliance on HR outsourcing.

A second dimension is "Responsibility for HR activities", which indicates the extent of devolution of HR activities to line managers. HR devolution is a growing trend (Conway \& Monks, 2010; Sheehan, 2005) that occurs when HR responsibilities are relocated from the HR professionals to line managers (McCracken \& McIvor, 2013). Line managers' contribution to the organization includes the ability to adopt a range of responsibilities ranging from "hard" and "soft" human resource practices (Cunningham \& Hyman, 1999) and has been long accepted in the HRM literature (Delmotte \& Sels, 2008; Larsen \& Brewster, 2003). In the CRANET survey, we can find 4 different questions related to the responsibility of line managers or the HR department, one for each of the following HR activities:

- Compensation and benefits

- Recruitment and selection

- Training and development

- Workforce outplacement.

Each question has four alternative answers:

- Main responsibility with HR department

- Main responsibility with HR department, with the contribution of line managers 
- Main responsibility with line managers, with the contribution of the HR department

- Main responsibility with line managers.

\subsection{Interviews}

As mentioned above, informal interviews with HR providers were undertaken by the researcher at local industry seminars in order to facilitate our understanding of a wide range of issues the decision to outsource HR functions. Namely we were interested

- To determine the HR services mainly outsourced by Spanish organization.

- The profile of organization that outsource HR function

- The reasons why Spanish organization decide to outsource.

With the participant's permission each conversation were recorded and later transcribed and analyzed. The interviews were based upon the HR external provider perceptions and the HRO practice in order to gain some understanding into the lived experience of HR external providers working with firms.

Adopting common guidance in qualitative analysis the data were therefore organized, and displayed, and codes were then developed ensuring that data interpretation remains directly linked to the words of the participants and that emergent patterns and themes were recognized across the data

\section{Results}

\subsection{Step 1- from CRANET survey}

In order to study the information provided in the database and thus identify the relationships between the independent variable (year) and the dependent variable (HRM services) we first constructed a cross table using SPSS. As can be noted in each of the areas (see Table 1), the outsourcing of HRM services has broadly experienced an important growth over the last decade in Spain. According to the data, the use of external HRM services in general has increased from 1999 to 2014. Table 1 shows the most commonly outsourced HRM activities in both years and Figure 1 illustrates this evolution.

\begin{tabular}{|l|r|r|r|r|}
\cline { 2 - 5 } \multicolumn{1}{c|}{} & $\begin{array}{c}\text { Compensation \& } \\
\text { Benefits }\end{array}$ & $\begin{array}{c}\text { Recruitment \& } \\
\text { Selection }\end{array}$ & $\begin{array}{c}\text { Training \& } \\
\text { Development }\end{array}$ & $\begin{array}{c}\text { Workforce } \\
\text { outplacement }\end{array}$ \\
\hline $\mathbf{1 9 9 9}$ & $21.7 \%$ & $57.4 \%$ & $82 \%$ & $11 \%$ \\
\hline $\mathbf{2 0 1 4}$ & $68.4 \%$ & $65.3 \%$ & $73.5 \%$ & $48 \%$ \\
\hline
\end{tabular}

Table 1. Use of outsourcing for HRM activities. Comparison 1999-2014

The results suggest that in Spain in 1999 significantly fewer companies outsourced HRM activities related to workforce outplacement and compensation and benefits than in 2014. A less remarkable increase of outsourcing can be seen for recruitment and selection. Regarding training and development, which is the most commonly outsourced function, a slight decrease can be observed.

We provide to explain the evolution of HR outsourcing thought a diagram which represent our four dependent variables, namely:

- compensation and benefits

- Recruitment and selection

- Training and development

- Workforce outplacement. 


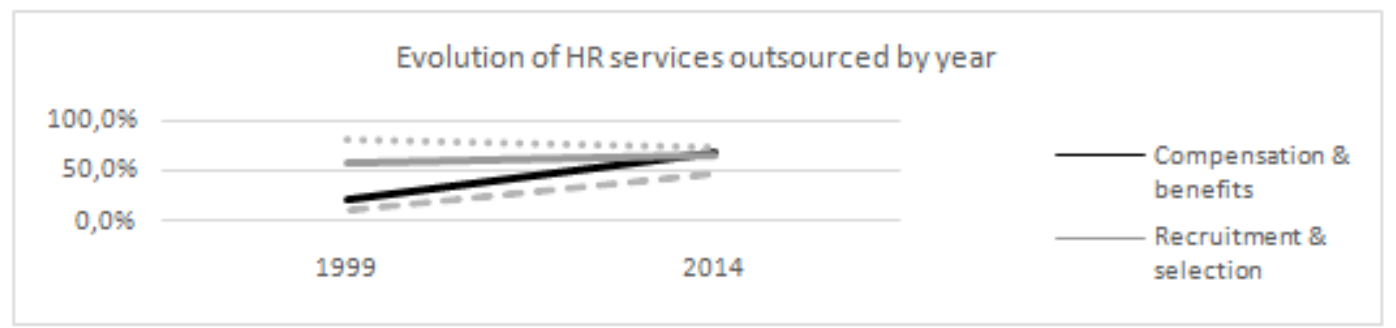

Figure 1. Evolution of HR services in Spain

A non-parametric test was carried out where the null hypothesis that arises is whether the distribution of the variable in the two years is the same. For this, the Chi-square test is performed, to test and prove rate differences among year for each one of the above variables. The results show that the most outsourced HR service is training and development in 1999 with $82 \%$, and $73.5 \%$ in 2014 but no significant differences were observed since the $\mathrm{P}$ value is $>0.05$. The second most outsourced group of HR activities is recruitment and selection: $57.40 \%$ in 1999 and 65.3\% in 2014. Compensation and benefit is outsourced for few companies in 1999 (21\%) while in 2014 organizations making use of outsourcing for this activity is much more common. The activity that organizations are less likely to outsource is Workforce Outplacement (11\% in 1999 and 48\% in 2014).

According to a Pearson chi-square test of association compensation and benefit, and workforce outplacement vary significantly among years, the $\mathrm{P}$ values is less than 0.05 which indicate a significant statistical differences, so we can reject the null hypothesis, thus assuming that the variable does not have a homogeneous behavior in the two years analyzed. With regard to recruitment and selection and training and development HRM service no significant differences were found since the $\mathrm{P}$ value is $>0.05$. Intensity of outsourcing was measured as the number of the four activities outsourced, divided by the maximum number of activities that could be outsourced by the firm. The data analysis included descriptive statistics and at-test. The t-test was used to test whether significant differences existed in the intensity of outsourcing means between organizations in the two years of study.

A first analysis shows that the mean level of HR services outsourced in Spain in 1999 is 1.72 versus a mean of 2.56 in 2014 (average on a 4-point scale). Further analysis (t-test-analysis) shows that the differences between mean outsourcing in the different years are significant $(\mathrm{p}<0.05)$. We also selected the Mann-Whitney test, which uses ranks of frequency, often used when comparing ordinal rating scales (Oakes, 1998). The analysis shows significant differences between 1999 and $2014(\mathrm{Z}=\mid$ 3.9, $\mathrm{p}<0.05)$, thus showing that the intensity of outsourcing HR activities is now greater than in 1999, that is, in general, organizations outsource more HR activities than in the past.

So far, we have mainly presented an overview of the major differences found between 1999 and 2014 with regard to the degree of HR outsourcing.

However, it is necessary to introduce other independent variables beyond the moment in time, in order to understand these differences more accurately.

Thus, a series of logistic regression models have been performed to be able to predict the factors bearing on the further utilization of HR outsourcing in Spanish organizations, by including as control variables the year, size of organization and industry sector. Logistic regression has been identified as the most relevant model for categorical data response (Agresti, 2013) as it predicts the probabilities of different possible outcomes of a categorically distributed target variable given a set of independent features (Sweet \& Grace-Martin, 1999). In accordance with this statement, it was decided to use binomial logistic regression to examine what is the relationship between

- outsourcing of compensation and benefits with the independent variables responsibility for compensation and benefit, 
- outsourcing of recruitment and selection with responsibility for recruiting and selecting staff

- outsourcing of training and development with the responsibility for training and development and

- the relationship between outsourcing of workforce outplacement with responsibility for workforce outplacement.

That is, we investigate whether companies that devolve HR activities to the line also increase or decrease the outsourcing of those HR activities.

In the first case we wanted to test the probability that companies outsource compensation and benefits according to who is responsible for the functions of compensation and benefits and this is based on the estimation of the following general logistic regression:

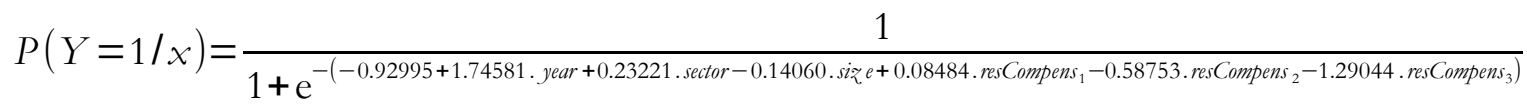

Given that this independent variable was categorized as follows: 1 HR department, 2. HR department with Line 3. Line with HR department, 4. Line manager, the higher the number in the categorization, the more devolved the activity. The Omnibus Tests of Model Coefficients is used to check that the models (with variables included) is an improvement over the baseline model. It uses chi square tests to see if there is a significant difference between the Log-likelihoods (the reference is HR department) of the baseline model and the new model. Here the chisquare is highly significant (chi-square $=69.980, g l=7, p<.000$ ) so our new model is significantly better.

The same Omnibus Tests of Model Coefficients was performed for the four cases of HR responsibility, namely: Compensation and benefits, Recruitment and selection, Training and development, Workforce outplacement.

For the variable "Responsibility for compensation and benefit", which was considered categorical, and after controlling for year, size and sector, the first category (HR department) was taken as reference. We can notice that the negative value of $\beta$ for the fourth category (Line Manager) indicates that, by increasing the line manager's responsibility for compensation and benefit will decrease the probability of using outsourcing of compensation and benefit compared to the organizations where the responsible for this HR activity is the HR department.

This is corroborated by the $\operatorname{Exp}(\beta)$ lower than $1(0.27)$.This latter, measures this relationship and indicates that the probability of using outsourcing was approximately $73 \%$ (1- 0.27) lower in companies whose responsible for compensation and benefits is the line manager than in those where the responsibility lies on the HR department. The odds ratio obtained from the logistic regression $(\mathrm{OR}<1(0.27)$, is shown in Table 2 and indicates how many times higher the odds of occurrence are for each one unit increase in the independent variable. In other words, organizations are more likely to outsource the functions of compensation and benefits when the responsible for this function (compensation and benefit) is the HR Department.

Thus, we have found an inverse relationship between devolution and outsourcing of compensation and benefits tasks, that is, the less companies devolve these tasks, the more they tend to outsource them.

\begin{tabular}{|c|c|c|c|}
\hline & B & Sig. & $\operatorname{Exp}(B)$ \\
\hline Responsibility for P\&B HR department (Ref) & & $0.01^{*}$ & \\
\hline Responsibility for P\&B (HR department with Line) & 0.08 & 0.80 & 1.08 \\
\hline Responsibility for P\&B (Line with HR department) & -0.58 & 0.11 & 0.55 \\
\hline Responsibility for P\&B (Line manager) & -1.29 & $0.01^{*}$ & 0.27 \\
\hline Year(1) & 1.74 & $8.61 \mathrm{e}-10 * * *$ & 5.73 \\
\hline Small Company (Ref) & & 0,93 & \\
\hline Medium Company & 19.91 & 1 & 4.47 \\
\hline Large Company & 19.77 & 1 & 3.88 \\
\hline Sector 2 group: prim+sec and tert(1) & 0.23 & 0.37 & 1.26 \\
\hline
\end{tabular}

Signif. codes: 0 '***', 0.001 '**', 0.01 '*', 0.05 '.', $0.1^{\prime \prime}$ ' 1

Table 2. Binary logistic regression model to predict the probability to outsource compensation and benefits $(\mathrm{P} \& \mathrm{~B})$ according to the degree of devolution these tasks 
The same analysis technique was performed to model the probability that companies use outsourcing for recruitment and selection according to who is responsible for these functions. Thus, the models describe the tendency of respondents to outsource their recruitment and selection and find out if it increased or decreased depending on who is responsible for recruiting and selecting employees. Based on the Omnibus Tests of Model Coefficients, the significance of model was 0.00 .

\begin{tabular}{|c|c|c|c|}
\hline & B & Sig. & $\operatorname{Exp}(B)$ \\
\hline Responsibility for R\&S (Ref) & & 0.53 & \\
\hline Responsibility R\&S (HR dp with Line) & 0.67 & 0.20 & 1.96 \\
\hline Responsibility R\&S (Line with HR dp) & 0.71 & 0.15 & 2.03 \\
\hline Responsibility for R\&S (Line manager) & 0.76 & $0.04^{*}$ & 2.15 \\
\hline Year(1) & 0.55 & $0.04 *$ & 1.74 \\
\hline SizeLarge Company & 0.69 & 0.03 & 0.03 \\
\hline Sector: prim+sec and tert(1) & -0.78 & $0.00 * * *$ & 0.46 \\
\hline
\end{tabular}

Signif. codes: 0 '***', 0.001 '**', 0.01 '*', 0.05 '.', 0.1 ' ' 1

Table 3. Binary logistic regression model to predict the probability to outsource recruitment and selection functions according to the degree of devolution of $R \& S$ tasks

The null hypotheses for the model can therefore be rejected, and the model can be considered useful, as shown in Table 4. After controlling for year, size and industry sector, when line managers are responsible to recruit and select employees, it is 2.15 times more likely to outsource recruitment and selection than when the responsible is HR department. In other words, the model predict that the responsibility of recruitment and selection in the line manager increases the probability of using outsourcing for recruitment and selection by 2.15 percent point. The Table 3 shows the results obtained.

\begin{tabular}{|l|r|r|r|}
\cline { 2 - 4 } \multicolumn{1}{c|}{} & B & \multicolumn{1}{c|}{ Sig. } & \multicolumn{1}{c|}{$\operatorname{Exp(B)}$} \\
\hline Responsibility T\&D (Ref) & & $\mathbf{0 . 0 0 ^ { * }}$ & \\
\hline Responsibility T\&D (HR dp with Line) & 1.58 & $\mathbf{0 . 0 0}^{*}$ & 3.58 \\
\hline Responsibility T\&D (Line with HR dp) & 1.84 & $\mathbf{0 . 0 0}^{*}$ & 4.19 \\
\hline Responsibility T\&D (Line manager) & 1.79 & $\mathbf{0 . 0 0 ^ { * }}$ & 5.98 \\
\hline Year (1) & -0.67 & $\mathbf{0 . 0 2} *$ & 0.50 \\
\hline SizeLarge Company & -0.20 & 0.40 & 0.61 \\
\hline Sector: prim+sec and tert(1) & -0.29 & 0.28 & 0.74 \\
\hline
\end{tabular}

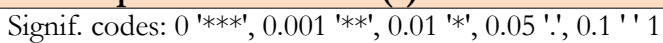

Table 4. Binary logistic regression model to predict the probability to outsource training and development functions according to the degree of devolution of T\&D tasks

The results of the logistic regression presented in Table 4 show that, when those responsible for training and development are the line managers the use of outsourcing for training and development is 5.98 times higher than when the responsibility lies on the HR department, and when responsible is the line manager with HR department is 4.19 times more probably to use outsourcing of training and development than when the responsible is the HR department. And when the responsible is HR with line, is 3.58 times more probably to outsource than when the responsibility lies on HR department.

The model is statistically significant (Chi-square=19.79; pb.0006) with a Pseudo $\mathrm{R}_{2}$ when the independent variables are introduced Turning to training and development.

In other words, the probability of using outsourcing for training and development increases as organizations devolve more to line managers or to line managers which work together with HR department or when HR department work in cooperation with line.

We also performed a regression analysis (Table 4) with the aim to predict the probability that companies use outsourcing for outplacement according to who is responsible for this function within the company. As noted, the fact that the responsibility for the functions of Workforce expansion / reduction lies on the HR department 
in conjunction with line, the line With HR department and the line manager, carry out a higher probability of use of outsourcing for Workforce expansion/reduction than when the responsibility for such task falls exclusively to the HR department. After controlling for year, size and sector we can say that when those responsible for outplacement are the line managers, there are 14.70 times more probability to outsource outplacement than when those responsible are the HR department. When responsibility lies on line managers with HR department, it is 9.63 times more probably to use outsourcing for outplacement than when the responsible is the HR department. And when the responsible is HR with line, is 14.60 times more probably to outsource than when the responsibility lies on HR department. Thus, the more companies devolve these tasks, the more they tend to outsource them.

\begin{tabular}{|c|c|c|c|}
\hline & B & Sig. & $\operatorname{Exp}(B)$ \\
\hline Responsibility Outplacement (Ref) & & 0.05 & \\
\hline Responsibility Outplacement (HR dp with Line) & 2.68 & $0.01^{*}$ & 14.60 \\
\hline Responsibility Outplacement (Line with HR dp) & 2.26 & $0.03^{*}$ & 9.63 \\
\hline Responsibility Outplacement (Line manager) & 2.68 & $0.01 *$ & 14.70 \\
\hline Year(1) & 1.93 & $0.00^{*}$ & 6.92 \\
\hline SizeLarge Company & 19.16 & 1.00 & \\
\hline Sector 2 group: prim+sec and tert(1) & -0.61 & 0.051 & 0.54 \\
\hline
\end{tabular}

Table 5. Binary logistic regression model to predict the probability to outsource outplacement according to the degree of devolution of outplacement tasks

\subsection{Step 2 - from the interview}

In order to answer our research question the interviews asked to HR external provider some key questions. Attention was given to the formulation of the questions to avoid lack of clarity or directed responses:

\section{- HRM services mainly outsourced and number of employee in the firms that outsource HR function}

Participants in the interview were asked about the HR services commonly outsourced by Spanish companies. HR providers gave mixed responses; we noted that organizations outsource mainly pay and benefits, recruitment and selection, training and development and less commonly outplacement. Due to the fact that in the interviews we noted that external provider described the type of organization by the number of employee formerly hired and according to the main functions clients are likely to outsource, we decided to analyze these two point together. The major finding of the interview was the identification of different group of companies, namely small, medium and large. External providers, state that small companies(less than 50 employees) tend to outsource all general HR activities, including recruitment and selection, training and development, pay and benefits and workforce outplacement (firm C). Thus, smaller companies, do not find it necessary to develop internally HR activities or external providers are deemed to provide more knowledge and expertise on all matters concerning human resources and therefore decide to outsource their HRM functions. Medium firms (50-250 employee) contract mainly recruitment and selection and pay and benefits (firm A) probably as a result of HRM department's ability to carry out most of the HRM function and thus covers most of their needs; large companies (more than 250 employee) are mainly interested in outsource training and development (firms B, D, E)and pay and benefits (firm B and E) and less commonly outplacement (firm F). Therefore, about the first two points we found that types of organization may influence the HR function outsourced.

\section{- Reasons why Spanish organization decide to outsource}

The third question examines the main reasons of why Spanish organization decide to outsource HR functions. On the one hand, HR providers noted that organizations have an overarching preference to outsource in order to get more specialized HR expertise: 
"I think my customers want best-qualified service provider that are able to support their operations and function. They decide to outsource training for example because we have the necessary skills and facilities and condition to train. Training supports firms' business strategy and is an important part of the workplace culture, they need us because we know how to do it in the best way" (firm B). This was confirmed elsewhere:

"Organization lack of qualified HR manager in house, and they know this is a weaknesses, so they decide to hand off a task they know they can't handle properly, to someone with skills and qualification... lack qualifications to fulfill the responsibilities in house, or may not even have a HR department in house and outsource all HR activities as often happens" (firm C).

Here the expertise and skills of the providers are also evidenced, same conclusion come from firm E: "Organization want rapidity and want professionals with competences". And firm A: "Organizations want to have the guarantee of high qualified employees and need to contract out them in some cases"

Responses given by providers suggests that firms outsource because they do not have expertise to handle some HR activities in-house and companies calling in an expert have the opportunity to benefit from the perspective of an outside qualified provider, ensuring top quality service. Through experts, organization can have access to professionals' skills competencies and capabilities, be freed from administrative tasks and thereby focus on the priorities of strategic nature. This is particularly helpful for organizations that do not possess enormous baggage of knowledge, subject matter experts or access to advanced technologies. HR providers highlighted also the organization's need to contract out training in order to complement the workforce skills, as they can often offer up to date specific experience, that can help firms to develop new products and thus be innovative:

"The primary reason for outsourcing training is due to the lack of in-house skills and knowledge or even resources. If a firm lack the resources, outsourcing training can help to get required expertise that can help them to keep up to date. External providers can also supplement their internal resources. An internal training department may be very good giving instruction on what to do but it may need support in the area of development of a specific product, for example or...or software or production. To this fact we may add that for example some supervisor in the organizations do not have experience in the area, they need training and, therefore, need to rely on outside providers. For example, if the engineer at the head of a group of engineers wants to move towards agile project, but have no expertise in the area, outsourcing may be the best choice to go. And even if some of them like the direct supervisor know they may prefer to outsource...." (Firm D).

"Organization require employees to stay up-to-date in new process, technologies, techniques, and outsource training can help employee to acquire new information on an efficient way, we offer training online or through seminars or classroom in an effective way... we teach them program, and if organization do not have staff for this function then they ask us to take on this responsibility, to stay competitive and innovate a company need to keep up with technologies" ... outsourcing provide a quick response to meet the company's needs “(Firm B).

"We have the ability to perform rapidly and organization need this". (Firm E)

"Organizations aim to bring into the market new top-range products and technologies and this can be reach by training employee on how to sell or supply a product. This allow a product to reach customers much faster and firms know we can be useful in this kind of things" (Firm E).

It is therefore revealed on the one hand the need of firms to keep up to date with new technologies but also the need to develop creative people and innovative organizations rapidly. The development and training of employees is crucial to organizational success, innovation, and overall productivity.

Employee are expected to keep themselves informed and external providers are the best choice to ensure the correct training. Furthermore HR providers believed that they help those organization who may want to save 
time to HR manager, and in some cases line manager and support their lack of expertise with recruitment and training process:

"HR manager do not have time to recruit people and even when they can count with the support from direct superior we are asked to help them as they know that those line are not aware how to conduct an interview for example. Or in the case of training those line believes a particular course will improve job performance but they do not have the necessary time to hold the course during their working hours."'(Firm A)

Indeed this is confirmed also by other providers which declared that direct supervisors, despite being experts, may lack the time to train employee:

“... because although some of the staff is trained such as the direct supervisors or the line manager ... they may not have enough knowledge about how to train or even time to dedicate themselves training employees" (Firm D)

As shown in Table 7 collectively all the respondents expressed the conviction that organization decide to outsource because they lacked the necessary internal skills and experience in the HR professional and adversely to the initial expectations of the researchers and to the prior literature (Reichel \& Lazarova, 2013), external providers also come into play not only when HR manager do not have the time to develop some HR function but also when line manager do not have the time to undertake such activities.

\begin{tabular}{|c|c|c|c|}
\hline Provider & $\begin{array}{l}\text { HRM services } \\
\text { mainly } \\
\text { outsourced }\end{array}$ & $\begin{array}{l}\mathrm{N}^{\circ} \text { of employee } \\
\text { in the firms }\end{array}$ & $\begin{array}{c}\text { Reasons why Spanish organization decide to } \\
\text { outsource }\end{array}$ \\
\hline A & $\begin{array}{l}\text { Recruitment \& } \\
\text { Selection } \\
\text { Pay and benefits }\end{array}$ & $\begin{array}{l}50-250 \\
\text { Medium }\end{array}$ & $\begin{array}{l}\text {-Save HR manager or Line manager time, focus on } \\
\text { their day to day activities } \\
\text {-Lack knowledge of line manager to interview } \\
\text { employee } \\
\text {-Guarantee of a high qualified employee }\end{array}$ \\
\hline $\mathrm{B}$ & $\begin{array}{l}\text { Training } \\
\text { Pay and benefits }\end{array}$ & $\begin{array}{l}50-250 \\
\text { Medium }\end{array}$ & $\begin{array}{l}\text { - Looking for more specialized providers } \\
\text { - Looking for Innovation, and experience } \\
\text {-Keep employee up to date (for example with some } \\
\text { software etc.) }\end{array}$ \\
\hline $\mathrm{C}$ & $\begin{array}{l}\text { General HR } \\
\text { function, } \\
\text { recruitment, } \\
\text { training, pay and } \\
\text { benefits }\end{array}$ & $\begin{array}{l}\text { Less than } 50 \\
\text { Small }\end{array}$ & -Lack of qualified HR manager \\
\hline $\mathrm{D}$ & $\begin{array}{l}\text { Training, } \\
\text { coaching, and less } \\
\text { common } \\
\text { outplacement }\end{array}$ & $\begin{array}{l}\text { More than } 250 \\
\quad \text { Large }\end{array}$ & $\begin{array}{l}\text { - Keep up to date } \\
\text {-Lack of specialized department for outplacement } \\
\text { - Lack of expertize for training } \\
\text {-Lack of time of direct supervisor to train employee }\end{array}$ \\
\hline $\mathrm{E}$ & $\begin{array}{l}\text { Training \& } \\
\text { Development }\end{array}$ & $\begin{array}{l}\text { More than } 250 \\
\text { large }\end{array}$ & $\begin{array}{l}\text {-Looking for professionals competences and rapidity } \\
\text {-Innovation }\end{array}$ \\
\hline
\end{tabular}

Table 6. HRM services mainly outsourced, number of employee and reasons

\section{Conclusions and discussion}

The findings of our research, both from the quantitative and the qualitative data revealed some interesting outcomes, which are now discussed.

First, our findings show differences in the use of HR external providers over the years, thus confirming several publications that claim there has been a substantial increase in the HR outsourcing over the last decade (Beregszaszi \& Hack-Polay, 2015; Galanaki \& Papalexandris, 2007; Kakabadse \& Kakabadse, 2002), becoming 
increasingly common for organizations to subcontract specific services (Woodall et al., 2009). This was confirmed by the CRANET survey and by the interviews. The most significant differences were in the use of external providers for HR activities related to compensation and benefits, which has grown 46.7\% since 1999 . This result is consistent with both interviews carried out where we can notice that the most commonly outsourced activities are pay and benefits and training and development and that of Cook (1999), who argues that by the late 1990 s, about $90 \%$ of firms outsourced at least some (mostly administrative) HR practices, such as compensation and benefits (Cook, 1999). The descriptive analysis has shown that this general increasing trend in the use of human resource external providers has continued to date.

Second, this study intended to be able to answer the research question and test to what extent the increasing trend of HR outsourcing is related to a strong focus on HRM devolution which is also the independent variable used in the regression

From CRANET survey we found clear evidence that the probability of HRO is more likely when there is a movement of responsibility from HR departments to line managers.

Based on the previous discussion and from both the quantitative and qualitative results, we present a propositions related to HR outsourcing in the Spanish context

\section{Proposition 1 (P1): A strong focus on HRM devolution is positively related to the level of HR outsourcing.}

Generally speaking, we found reasonably good support for the propositions formulated., When the person responsible for recruitment and selection, training and development and workforce outplacement are line managers or when decisions are taken in cooperation, the probability of HR outsourcing recruitment and selection, training and development and workforce outplacement increase respectively. This may suggest that line managers simply do not want to take such HR responsibilities or may not have either the time (McConville \& Holden, 1999), expertise, training, knowledge (Cunningham \& Hyman, 1995), or even perceive themselves to be people managers (Cascón-Pereira \& Valverde, 2014) to carry out these HR functions, or they may not have the appropriate business focus to deal with problems related to these tasks. This particular business strategy adopted by the organization to devolve HR task to line is significantly related to the decision to outsource. This finding is consistent with our interviews which further revealed that outsourcing decisions were also influenced by the lack of knowledge or time of line manager to carry out some specific HR function and also is confirmed by observations made by Larsen and Brewster (2003). Their research showed that in the last few years the HR department's work and responsibility are substantially reduced, thereby leading to a liberation of HR professionals from the hard toil of conducting routine jobs (Whittaker \& Marchington, 2004), this devolvement of HR task to line managers has increased concurrently with the growth in outsourcing of many HR role. Moreover, we highlight that our outcomes is in contrast to what reported by Reichel and Lazarova (2013), which suggested that outsourcing is less frequent in organizations where many of the traditional HR activities are devolved to the line. We could point to the fact that Spain was not included in their research, whereas our research is focused just in the Spanish background, thus, the context is likely to have a different impact in the results.

The probability to outsource more when increasing the responsibility of line managers or when HR department and line managers share the responsibility could be attributed to the fact that the role of line managers complements that of external providers by providing the necessary closeness to employees and local or unit know-how (line managers) alongside the expert HR knowledge of HR services external providers.

Thus, for example, simultaneously devolving recruitment and selection allows determining very exactly the needs of a unit or department, while also availing of a number of professionally recruited high skilled applicants. In the case of training and development, line managers, because they work closer to their teams, have the necessary information about the skills or the lack of right competencies of each employee and suggest training that best match their needs, while an outside training provider may provide the most up-to-date know-how about the topic. Our interviews revealed that one of the reason cited by two providers why organizations decide to outsource is the lack of specific knowledge of line manager to recruit or train employee. We found that line 
manager are aware of what is needed but it may be difficult for them undertake defined task such interview people or train them and being so, they prefer to outsource. These results correspond to those of Gibb (2003) and add value to his argument that considered that line managers may not be able to manage, in the same excellent way that an expert, the patterns and practices of training and development or even train and coach as specialists. Other authors (Larsen \& Brewster, 2003) claims that line managers could be considered responsible for training and development but in some cases intervention of external experts would be deemed necessary in order to solve problems arising from an important problem or quarrel that caused access to training, especially when it turn into a legal issue. When line manager decide to outsource training and development it may be due to the fact that they feel awkward or insecure in their ability to perform training and development tasks or even have more than enough to do without having to carry out training functions (Brewster \& Soderstrom, 1994). Indeed respondent declared that despite the fact that some personality inside the firm, as might be the line manager, have the knowhow to implement HR practices in general the may lack time or specific knowledge about how to carry out or execute that particular HRM practices. A number of studies have shown thatHR manager are responsible for designing and developing HRM practices, whereas line managers play an important role implementing those HR practices on the operational work floor (Hassan, Mansor \& Rahman, 2015) since they are in constant contact with the employees. However, despite the fact that it is more logical to give management responsibility to the same manager who is closer to the employee (Cunningham \& Hyman, 1995), line manager may decide for a "liquidation of the task" considering the latter as the likelihood to outsource this function to external training providers (Heraty \& Morley, 1995) ensuring access to specialized resources and skills residing in the provider firms and taking benefits from their noteworthy services (Lahiri, 2015). Line manager are in charge of analyzing the weakness or the lack of knowledge of employees and examining the needs of training and select people to be trained whereas external specialist are those responsible for developing policies and translate them into concrete action (Heraty \& Morley, 1995).

Finally, in the case of outplacement, which tends to entail legal issues, the co-operation between line managers and expert external providers may be totally necessary. When Outplacement programs are outsourced it provides a high level of support and service and both facilitate the positive reemployment outcomes for employee and allow organizations achieve beneficial outcomes (Westaby, 2004). For these sets of HR functions, thus, we can say that the strategy of devolvement of HR tasks to the line is significantly related to the decision to outsource. Instead, we are not in a position to make a similar claim for outsourcing pay and benefits when these tasks are devolved to the line. No statistically significant correlation was found for this function. Indeed, our results indicate that the probability to outsource pay and benefit decreases when the responsibility for this task lies on line managers. Line managers assume the role of executors of these policies (Valverde, Ryan \& Soler, 2006), outsourcing less. This could be interpreted that line managers who take on pay and benefit role are those who try to protect their staff and ensure their fair remuneration (Larsen \& Brewster, 2003) and that HR department takes into consideration the idea of the line managers, in order to propose compensation and benefits. When line managers are responsible, the HR department may have more confidence that line managers implement and disseminate employment decisions rightfully and in compliance to corporate policy (Valverde et al., 2006). Researcher can use this study as a springboard for further analysis of relationship and interplay between devolution and HRO decision.

\section{Declaration of Conflicting Interests}

The authors declared no potential conflicts of interest with respect to the research, authorship, and/or publication of this article.

\section{Funding}

The authors received no financial support for the research, authorship, and/or publication of this article. 


\section{References}

Agresti, A. (2013). Categorical Data Analysis. In International Encyclopedia of Statistical Science (pp. 206-208).

Alewell, D., Hauff, S., Thommes, K., \& Weiland, K. (2009). Triggers of HR outsourcing decisions - an empirical analysis of German firms. The International Journal of Human Resource Management, 20(7), 1599-1617. https://doi.org/10.1080/09585190902985228

Bart, V.A., Mary, O., \& Marcel P.T. (2008). The Productivity Gap between Europe and the United States: Trends and Causes. Journal of Economic Perspectives, 22(1), 25-44. https://doi.org/10.1257/jep.22.1.25

Belcourt, M. (2006). Outsourcing - The benefits and the risks. Human Resource Management Review, 16(2), 269-279. https://doi.org/10.1016/j.hrmr.2006.03.011

Beregszaszi, J., \& Hack-Polay, D. (2015). Off the overload: The growing HR outsourcing industry in emerging European economies - the case of Hungary. European Journal of International Management, 9(4), 409-424. https://doi.org/10.1504/EJIM.2015.070227

Brewster, C., Mayrhofer, W., \& Reichel, A. (2011). Riding the tiger? Going along with Cranet for two decades A relational perspective. Human Resource Management Review, 21(1), 5-15.

https://doi.org/10.1016/j.hrmr.2010.09.007

Brewster, C., \& Soderstrom, M. (1994). Human resources and line management. Policy and Practice in European Human Resource Management. London: Routledge.

Butler, M.G., \& Callahan, C.M. (2014). Human resource outsourcing: Market and operating performance effects of administrative HR functions. Journal of Business Research, 67, 218-224.

https://doi.org/10.1016/j.jbusres.2012.09.026

Cascón-Pereira, R., \& Valverde, M. (2014). Meanings attributed to management as an explanation for clinician managers' attitudes and professional identity. Gaceta Sanitaria, 28(6), 475-479.

https://doi.org/10.1016/j.gaceta.2014.05.009

Conklin, D.W. (2005). Risks and Rewards in HR Business Process Outsourcing. Long Range Planning, 38(6), 579-598. https://doi.org/10.1016/j.lrp.2005.09.004

Conway, E., \& Monks, K. (2010). The devolution of HRM to middle managers in the Irish health service. Personnel Review, 39(3), 361-374. https://doi.org/10.1108/00483481011030548

Cook, M.F. (1999). Outsourcing buman resources functions: Strategies for providing enbanced HR services at lower cost. Amacom.

Cooke, F.L., Shen, J., \& Mcbride, A. (2005). Outsourcing HR as a competitive strategy? A literature review and an assessment of implications. Human Resource Management, 44(4), 413-432. https://doi.org/10.1002/hrm.20082

Cunningham, I., \& Hyman, J. (1995). Transforming the HRM vision into reality: The role of line managers and supervisors in implementing change. Employee Relations Employee Relations Personnel Review, 17(6), 5-20. https://doi.org/10.1108/01425459510103451

Cunningham, I., \& Hyman, J. (1999). Devolving human resource responsibilities to the line for personnel? Personnel Review, 28(1/2), 9-27. https://doi.org/10.1108/00483489910248947

Chiang, F., Chow, I. H.-S., \& Birtch, T. (2010). Examining human resource management outsourcing in Hong Kong. The International Journal of Human Resource Management, 21(15), 2762-2777.

https://doi.org/10.1080/09585192.2010.528658

Delmotte, J., \& Sels, L. (2008). HR outsourcing: threat or opportunity?. Personnel Review, 37(5), 543-563. https://doi.org/10.1108/00483480810891673

Dewettinck, K., \& Remue, J. (2011). Contextualizing HRM in comparative research: The role of the Cranet network. Human Resource Management Review, 21(1), 37-49. https://doi.org/10.1016/j.hrmr.2010.09.010 
Edvardsson, I.R., \& Teitsdóttir, U.D. (2015). Outsourcing and financial crisis: Evidence from Icelandic service SMEs. Employee Relations, 37(1), 30-47. https://doi.org/10.1108/ER-11-2013-0168

Espino Rodríguez, T.F., \& Padrón Robaina, V. (2006). A review of outsourcing from the resource-based view of the firm. International Journal of Management Reviews, 8(1), 49-70. https://doi.org/10.1111/j.1468-2370.2006.00120.x

Fabregá, M.B., \& Nicolau, A.R. (2016). Emprendimiento y supervivencia empresarial en época de crisis: El caso de Barcelona. Intangible Capital, 12(1), 95-120.

Galanaki, E., \& Papalexandris, N. (2007). Internationalization as a determining factor of HRM outsourcing. The International Journal of Human Resource Management, 18(8), 1557-1567. https://doi.org/10.1080/09585190701502687

Gibb, S. (2003). Line manager involvement in learning and development Small beer or big deal?. Employee Relations, 25(3), 281-293. https://doi.org/10.1108/01425450310475865

Gilley, K.M.M., Greer, C.R., \& Rasheed, A.A. (2004). Human resource outsourcing and organizational performance in manufacturing firms. Journal of Business Research, 57(3), 232-240. https://doi.org/10.1016/S01482963(02)00304-1

Glaister, A.J. (2014). HR outsourcing: the impact on HR role, competency development and relationships. Human Resource Management Journal, 24(2), 211-226. https://doi.org/10.1111/1748-8583.12031

Greer, C.R., Youngblood, S.A., \& Gray, D.A. (1999). Human resource management outsourcing: The make or buy decision. Academy of Management Executive, 13(3), 85-96. https://doi.org/10.5465/AME.1999.2210317

GrupoUno CTC. (2015). Primer estudio GrupoUno CTC sobre la evolución de la externalización de procesos de negocio en España.

Hartman, P.L., Ogden, J.A., \& Hazen, B.T. (2017). Bring it back? An examination of the insourcing decision. International Journal of Physical Distribution \& Logistics Management, 47(2/3), 198-221. https://doi.org/10.1108/IJPDLM-09-2015-0220

Hassan, M.A., Mansor, N.N.A., \& Rahman, W.M.Z.W.A. (2015). Do line managers' have "linking pin" in HR roles?. Intangible Capital, 11(1), 1-12. https://doi.org/10.3926/ic.483

Heraty, N., \& Morley, M. (1995). Line managers and human resource development. Journal of European Industrial Training, 19(10), 31-37. https://doi.org/10.1108/03090599510095861

Hung Lau, K., \& Zhang, J. (2006). Drivers and obstacles of outsourcing practices in China. International Journal of Physical Distribution \& Logistics Management, 36(10), 776-792. https://doi.org/10.1108/09600030610714599

Iqbal, Z., \& Dad, A.M. (2013). Outsourcing: A Review of Trends, Winners \& Losers and Future Directions. International Journal of Business and Social Science, 4(8), 91-107.

Kakabadse, A., \& Kakabadse, N. (2002). Trends in Outsourcing: Contrasting USA and Europe. European Management Journal, 20(2), 189-198. https://doi.org/10.1016/S0263-2373(02)00029-4

Kenyon, G.N.N., Meixell, M.J.J., \& Westfall, P.H.H. (2016). Production Economics Production outsourcing and operational performance: An empirical study using secondary data. International Journal of Production Economics, 171, 336-349. https://doi.org/10.1016/j.ijpe.2015.09.017

Klaas, B.S., McClendon, J., \& Gainey, T.W. (1999). HR Outsourcing and Its Impact: the Role of Transaction Costs. Personnel Psychology, 52(1), 113-136. https://doi.org/10.1111/j.1744-6570.1999.tb01816.x

Klaas, B.S., McClendon, J.A., \& Gainey, T.W. (2001). Outsourcing HR: The Impact of Organizational Characteristics. Human Resource Management, 40(2), 125-138. https://doi.org/10.1002/hrm.1003

Kosnik, T., Wong-MingJi, D.J., \& Hoover, K. (2006). Outsourcing vs insourcing in the human resource supply chain: A comparison of five generic models. Personnel Review, 35(6), 671-684.

https://doi.org/10.1108/00483480610702728 
Lahiri, S. (2015). Does Outsourcing Really Improve Firm Performance? Empirical Evidence and Research Agenda. International Journal of Management Reviews, 0(June 2009), n/a-n/a. https://doi.org/10.1111/ijmr.12075

Lai, Y., Saridakis, G., Blackburn, R., \& Johnstone, S. (2016). Are the HR responses of small firms different from large firms in times of recession?. Journal of Business Venturing, 31(1), 113-131.

https://doi.org/10.1016/j.jbusvent.2015.04.005

Larsen, H.H., \& Brewster, C. (2003). Line management responsibility for HRM: What is happening in Europe?. Employee Relations, 25(3), 228-244. https://doi.org/10.1108/01425450310475838

Lilly, J., Gray, D., \& Virick, M. (2005). Outsourcing the Human Resource Function: Environmental and Organizational Characteristics that Affect HR Performance. Journal of Business Strategies, 2005, 55-73. Retrieved from: http://scholarworks.sisu.edu/mktds pub/20

Maley, J.F., Kowalkowski, C., Brege, S., \& Biggemann, S. (2015). Outsourcing Maintenance in Complex Process Industries: Managing Firm Capabilities in Lock-in Effect. Asia Pacific Journal of Marketing and Logistics, 27(5), 801-825. https://doi.org/10.1108/APJML-02-2015-0018

McConville, T., \& Holden, L. (1999). The filling in the sandwich: HRM and middle managers in the health sector. Personnel Review, 28(5/6), 406-424. https://doi.org/10.1108/00483489910286738

McCracken, M., \& McIvor, R. (2013). Transforming the HR function through outsourced shared services: Insights from the public sector. The International Journal of Human Resource Management, 24(8), 1685-1707. https://doi.org/10.1080/09585192.2012.725070

McGovem, P., Hope-Hailey, V., \& Stiles, P. (1989). Human resource management on the line?. Human Resource Management Journal, 7(4), 12-29. https://doi.org/10.1111/j.1748-8583.1997.tb00286.x

Monterrey-Meana, M. (2013). Nuevas tendencias en la externalización de procesos. Estudio de los casos Españoly Europeo. Dyna, 80(177), 4-12.

Parry, E., Stavrou-Costea, E., \& Morley, M.J. (2011). The Cranet International Research Network on Human Resource Management in retrospect and prospect. Human Resource Management Review, 21(1), 1-4. https://doi.org/10.1016/j.hrmr.2010.09.006

Quartey, S.H. (2013). Implications of HR Outsourcing for HR Practitioners Work Behaviors: Evidence from the Mobile Telecommunication Industry in Ghana. International Business Research, 6(11), 178-191. https://doi.org/10.5539/ibr.v6n11p178

Reichel, A., \& Lazarova, M. (2013). The effects of outsourcing and devolvement on the strategic position of HR departments 52.6. Human Resource Management, 52(6), 923-946. http://doi.org/10.1002/hrm

Saintemarie, A. (2011). Let's Outsource It! Overview of the Fast Growing Outsourcing Market. Warsaw: PMR Consulting.

Sanders, N.R., James, L., West, E., Locke, A., Moore, C.B., \& Autry, C.W. (2007). A Multidimensional Framework for Understanding Outsourcing Arrangements. Journal of Supply Chain Management, 43(4), 3-15.

https://doi.org/10.1111/j.1745-493X.2007.00037.x

Schuler, R.S. (1990). Repositioning the human resource function: transformation or demise?. The Executive, 4(3), 49-60. https://doi.org/10.5465/AME.1990.4274667

Sheehan, C. (2005). A model for HRM strategic integration. Personnel Review, 34(2), 192-209. https://doi.org/10.1108/00483480510579420

Shen, J. (2005). Human resource outsourcing: 1990-2004. Journal of Organisational Transformation \& Social Change, 2(3), 275-296. https://doi.org/10.1386/jots.2.3.275/1

Sweet, S.A., \& Grace-Martin, K. (1999). Data analysis with SPSS. In Data Analysis with SPSS: A First Course in Applied Statistics (4th Edition). 
Tremblay, M., Patry, M., \& Lanoie, P. (2008). Human resources outsourcing in Canadian organizations: An empirical analysis of the role of organizational characteristics, transaction costs and risks. The International Journal of Human Resource Management (Vol. 19). https:/ / doi.org/10.1080/09585190801953699

Valverde, M., Ryan, G., \& Soler, C. (2006). Distributing HRM responsibilities: a classification of organisations. Personnel Review, 35(6), 618-636. https:/ / doi.org/10.1108/00483480610702692

Vasconcelos, F.C., \& Ramirez, R. (2011). Complexity in business environments. Journal of Business Research, 64(3), 236-241. https://doi.org/10.1016/j.jbusres.2009.11.007

Westaby, J.D. (2004). The impact of outplacement programs or reemployment criteria: A longitudinal study of displaced managers and executives. Journal of Employment Counseling, 1(19), 19-28.

https://doi.org/10.1002/j.2161-1920.2004.tb00874.x

Whittaker, S., \& Marchington, M. (2004). Devolving HR responsibility to the line. Employee Relations, 25(3), 245-261. https://doi.org/10.1108/01425450310475847

Woodall, J., Scott-Jackson, W., Newham, T., \& Gurney, M. (2009). Making the decision to outsource human resources. Personnel Review, 38(3), 236-252. https://doi.org/10.1108/00483480910943313

Intangible Capital, 2018 (www.intangiblecapital.org)

Article's contents are provided on an Attribution-Non Commercial 4.0 Creative commons International License. Readers are allowed to copy, distribute and communicate article's contents, provided the author's and Intangible Capital's names are included. It must not be used for commercial purposes. To see the complete license contents, please visit https://creativecommons.org/licenses/by-nc/4.0/. 